\title{
The presence of polychlorinated biphenyls in yellow pigment products in China with emphasis on 3,3'-dichlorobiphenyl (PCB 11)
}

\author{
Hongtao Shang, Yingming Li, Thanh Wang, Pu Wang, Haidong Zhang, Qinghua Zhang*, Guibin Jiang \\ State Key Laboratory of Environmental Chemistry and Ecotoxicology, Research Center for Eco-Environmental Sciences, Chinese Academy of Sciences, Beijing 100085, China
}

\section{H I G H L I G H T S}

- PCB11 and other PCB congeners were analyzed with HRGC coupled with HRMS

- High concentrations of PCB11 and PCBs were detected in all pigment samples.

- PCB 11 was the major contributor of total PCB concentration.

- 12 Dioxin-like PCBs were investigated and WHO-TEQ were calculated.

\section{A R T I C L E I N F O}

\section{Article history:}

Received 19 April 2013

Received in revised form 17 September

2013

Accepted 24 September 2013

Available online 11 November 2013

\section{Keywords:}

3,3'-Dichlorobiphenyl

PCBs

Yellow pigment

Toxicity

\begin{abstract}
A B S T R A C T
A non-Aroclor PCB congener, 3,3'-dichlorobiphenyl (PCB 11) has recently attracted wide concerns because of its environmental ubiquity and specific sources potentially associated with yellow pigment production. In order to investigate PCB 11 and other PCBs in the yellow pigment products, 24 yellow pigment samples were collected from three different manufacturing plants in China. $\sum_{20}$ PCBs and PCB 11 were in the range of 50.7-9.19 $\times 10^{5} \mathrm{ng} \mathrm{g}^{-1}$ and $41.7-9.18 \times 10^{5} \mathrm{ng} \mathrm{g}^{-1}$, respectively, which was much higher than those reported in previous study. The corresponding TEQ values ranged between 0.16 and $4.21 \times 10^{3} \mathrm{ng} \mathrm{WHO}_{2005}-\mathrm{TEQ} \mathrm{kg}{ }^{-1}$. The contribution of PCB 11 to $\sum_{20} \mathrm{PCBs}$ reached up to $85.5 \%$ (median value) followed by PCB 28, РCB 77, and PCB 52 with contributions of $10.5 \%, 6.70 \%$, and $5.40 \%$, respectively. Significant differences were observed for PCB 11 concentrations among the different types of yellow pigment from the same plant and among the same sample types from different plants. The PCB 11 concentrations in diarylide yellow pigments produced from 3,3'-dichlorbenzidine were the highest in all the samples. It demonstrates that yellow pigment is a significant source not only for the widespread pollution of PCB 11 but also for other PCBs, especially for the lower chlorinated congeners.
\end{abstract}

(c) 2013 Elsevier Ltd. All rights reserved.

\section{Introduction}

Polychlorinated biphenyls (PCBs), one of the most famous "dirty dozen" persistent organic pollutants (POPs), used to be produced and commercially used as mixtures. Because of their specific properties such as good stability, low volatility, insulativity and non-flammability, PCBs have been applied in a series of industrial applications such as coating, links, flame retardants, paints, electronic appliances, heat-transfer systems and hydraulic fluids (Srogi, 2008). PCBs were targeted for elimination under the Stockholm Convention on POPs due to their environmental persistence, toxicity, and bioaccumulation properties, and could pose hazard to environment, biota and humans (UNEP, 2001). Although, PCBs were banned by most countries as early as the 1970s, they can still be detected in air, soil, water, sediment, and biota at a global scale,

\footnotetext{
* Corresponding author. Tel./fax: +86 1062849818.

E-mail address: qhzhang@rcees.ac.cn (Q. Zhang).
}

even in remote sites such as the polar regions, deep seas and high mountains (Ballschmiter et al., 1997; Stegeman et al., 2001; Wang et al., 2009; Li et al., 2012a,b).

With regard to PCB congeners, the 12 dioxin-like PCBs and six indicator PCBs usually gain the most attention, although the levels of these congeners have been declining in environment since PCBs were banned (DSEWPC, 1998; O'Reilly and Yarto, 2010; Dang et al., 2012). However, 3,3'-dichlorobiphenyl (PCB 11), a non-Aroclor PCB congener but unintentional by-product of manufacturing processes, has recently come under the spotlight. The occurrence of PCB 11 in the environment was noted by Litten et al. (2002) in surface water and wastewater from two wastewater treatment plants near pigment manufacturing facilities in the New York/New Jersey Harbor area in 2002. During subsequent years, PCB 11 was ubiquitously detected in water, suspended particulate material, biota, soil, and air even in the Polar Regions (King et al., 2002; Hu et al., 2008; Basu et al., 2009; Wang et al., 2010, 2012; Li et al., 2012a). And PCB 11 was reported as a dominant component in 
some places (King et al., 2002; Rodenburg et al., 2010; Baek et al. 2013; Grossman, 2013), even made the total PCBs concentration exceed the local standard in the Delaware River (Rodenburg et al., 2010). Some studies suggested that PCB 11 had some potentially toxic activities like calcium, dopamine, and thyroid hormone interference (Shain et al., 1991; Kodavanti, 2005).

In recent years, researchers have discussed several potential emission sources of PCB 11, such as municipal solid waste incinerators, degradation of more chlorinated CBs, release from Aroclor 1221, and paint and pigment manufacturing (King et al., 2002; Hu and Hornbuckle, 2010). In 1999, the US EPA (1999a,b) reported that PCBs were detected in pigments and had varied concentrations. Hu and Hornbuckle (2010) has investigated the distribution of PCB 11 in paint pigments purchased in the US and PCB 11 was detected in 13 of 33 analyzed paint pigments. High concentrations of PCB 11 were also observed in printing inks and various consumer goods (e.g., color magazine, color newspaper, brown (unprinted) cardboard and yellow plastic bag) which contain yellow pigments (Rastogi, 1992; Rodenburg et al., 2010). Increasing evidence has been yielded to take the yellow pigment manufacturing as the principal source of $\mathrm{PCB} 11$, in particular for diarylide yellow pigment which is made from bisdiazotized 3,3'dichlorobenzidine (Litten et al., 2002; Hu and Hornbuckle, 2010).

Occupational exposure during pigment manufacturing process and dermal contact with pigment products might be the main routes for human exposure to pigments (HSDB, 2003). China has the largest production of classic organic pigment in the world. According to the report of the China Dyestuffs Industry Association (CDIA) (CDIA, 2009), the production of organic pigment in 2008 was $1.85 \times 10^{5}$ metric tons among which $1.52 \times 10^{5}$ metric tons were exported. As the most important and commonly used type of pigment in printing and other applications (Herbst and Hunger, 2004), the annual production of organic yellow pigments was up to $2.0 \times 10^{4}$ metric tons in China (Yang and Zhang, 2011), of which a large proportion was diarylide yellow pigments. The organic pigment and relevant products might be an important source of PCB 11 in China.

Although a few studies have been performed on the presence of PCB 11 in pigments (Hu and Hornbuckle, 2010) and related consumer goods in the US (Rodenburg et al., 2010), to our knowledge, there is currently no published data on the contamination of PCB 11 and other PCBs in pigments and related products from China. This study was aimed to investigate and provide an overview of the concentration and distribution of PCBs in yellow organic pigments from China.

\section{Materials and methods}

\subsection{Samples and reagents}

\subsubsection{Samples}

The pigment samples were collected from three manufacturing plants (Table S1 in Supporting Information) in 2010: plant A was located in Beijing, plant B in Jiangsu province and plant $C$ in Shanghai. We collected 14 pigment samples in plant $A, 5$ in plant $B$, and 5 in plant C. 9 of them were monoazo yellow pigments, 14 samples were disazo yellow pigments, and one was quinophthalone pigment.

\subsubsection{Reagents}

All the organic solvents were pesticide residue grade from J.T. Baker (NJ, USA). Silica was purchased from Merck (silica gel 60, Darmstadt, Germany). Anhydrous sodium sulfate was purchased from Beijing Chemical Factory (China). Calibration standard solutions, ${ }^{13} \mathrm{C}_{12}$-labeled surrogate standards (68A-LCS, ${ }^{13} \mathrm{C}_{12}$-PCB 1,3 ,
$4,15,19,37,54,77,81,104,105,114,118,123,126,155,156$, $157,167,169,188,189,202,205,206,208$, and 209) and ${ }^{13} \mathrm{C}_{12}$-labeled injection standards (68A-IS, ${ }^{13} \mathrm{C}_{12}$-PCB 9, 52, 101, 138, 194) were purchased from Wellington Laboratories (Guelph, Canada). PCB 11 standard was purchased from Dr. Ehrenstorfer $\mathrm{GmbH}$ (Augsburg, Germany), the purity is $99.0 \%$.

\subsection{Sample extraction and analysis}

The method of sample extraction, cleanup, and instrumental analysis was modified according to US EPA method 1668A (US EPA, 1999a). About $1.0 \mathrm{~g}$ of sample was weighed accurately and then extracted with $50 \mathrm{~mL}$ mixture of acetone and hexane $(1: 1$, $\mathrm{v} / \mathrm{v}$ ) in a flat bottom flask by ultrasound for $45 \mathrm{~min}$. The clean-up procedure was based on our previous report (Liu et al., 2006). An aliquot of the extract contains $0.01 \mathrm{~g}$ pigment was spiked with $10 \mu \mathrm{L}$ of $100 \mathrm{ng} \mathrm{mL}^{-1}$ labeled surrogate standards. An anthropogenic isolation column ( $1.0 \mathrm{~g}$ silica gel, $4.0 \mathrm{~g} \mathrm{33 \%}$ basic silica gel, $1.0 \mathrm{~g}$ silica gel, $8.0 \mathrm{~g}$ acid silica gel $(30 \% \mathrm{w} / \mathrm{w}), 2.0 \mathrm{~g}$ silica gel and a thin layer of anhydrous sodium sulfate from bottom to up) was used for sample cleanup. The column was preconditioned with $80 \mathrm{~mL}$ of $\mathrm{n}$-hexane and eluted with $100 \mathrm{~mL}$ of n-hexane. Then the eluent was concentrated to approximately $20 \mu \mathrm{L}$ in a sample vial. $5 \mu \mathrm{L}$ of injection standards were added prior to instrumental analysis.

The PCBs were analyzed using a high resolution gas chromatograph (6890 N Network, Agilent Technologies, USA) coupled with a high resolution mass spectrometer (Autospec Ultima, Waters, USA) operating at a resolution of 10000 . The detailed conditions of HRGC/HRMS were described in our previous literature (Shang et al., 2013). Twelve dioxin-like PCBs (PCB 77, 81, 105, 114, 118, $123,126,156,157,167,169$ and 189), six indicator PCBs (РCB $28,52,101,138,153$, and 180), РCB 209, and PCB 11 were quantified.

\subsection{Quality assurance and quality control}

All the performance criteria met the US EPA 1668A method requirements. The limits of detection (LOD) were defined as signal/noise $(S / N)=3: 1$ and the isotopic ratios of the two main ion pairs were within $\pm 15 \%$ of the theoretical value. The LOD for PCBs, PCB 11 , and recovery of 68A-LCS were in the range of 2.50$515 \mathrm{pg} \mathrm{g}^{-1}, 46.6-1.33 \times 10^{3} \mathrm{pg} \mathrm{g}^{-1}$ and $27.4-136 \%$, respectively. Laboratory blanks ( $4 \mathrm{~g}$ anhydrous sodium sulfate) were analyzed paralleled to sample analysis. PCB 11 and some indicator PCBs (e.g., РCB 28, 52, 118, 138 and 153) were detected at very low levels in the blanks ( $<5 \%$ of the lowest concentration in the samples), so the results were not blank corrected.

\section{Results and discussion}

\subsection{Categories of the sampled pigments}

According to their chemical constitution, the organic pigments could be classified into six categories: azo, polycyclic, anthraquinone, dioxazine, triarylcarbonium and quinophthalone pigments (Herbst and Hunger, 2004). In this work, azo and quinophthalone pigment were collected. As one of the most widely used category (70\% of all organic pigments worldwide (ETAD et al., 1995)), azo pigments have the generic structure containing azo-group $(-\mathrm{N}=\mathrm{N}-$ ), which could be divided into monoazo pigment (single azo-group) and disazo pigments (two azo-groups). Most of monoazo pigments could be synthesized with acetoacetic arylides as coupling components (e.g., P.Y.1, P.Y.3, and P.Y.5). Another group of monoazo is taken 1-arylpyrazolones-5 as coupling components 
Table 1

Concentrations ( $\mathrm{ng} \mathrm{g}^{-1}$ ) and TEQ values ( $\mathrm{ng} \mathrm{WHO}_{2005} \mathrm{TEQ} \mathrm{kg}^{-1}$ ) of PCBs in the yellow pigment samples.

\begin{tabular}{|c|c|c|c|c|c|c|c|c|c|c|c|c|c|c|}
\hline & \multicolumn{13}{|c|}{ Azo pigment } & \multirow{3}{*}{$\begin{array}{l}\text { Q.P }^{\mathrm{d}} \\
\text { P.Y.138 }\end{array}$} \\
\hline & \multicolumn{7}{|c|}{ Monoazo yellow pigment } & \multicolumn{5}{|c|}{ Diarylide yellow pigment } & \multirow{2}{*}{$\begin{array}{l}\text { B.A.P } \\
\text { P.Y.16 }\end{array}$} & \\
\hline & P.Y.1 & P.Y.3 & P.Y.5 & P.Y.65 & P.Y.191 & L. $Y^{\mathrm{a}}$ & M.Y ${ }^{\mathrm{b}}$ & P.Y.12 & P.Y.13 & P.Y.14 & P.Y.17 & P.Y.81 & & \\
\hline PCB-11 & 244 & $\begin{array}{l}49.3- \\
1.93 \times 10^{4}\end{array}$ & 165 & 228 & 641-862 & 41.7 & 88.2 & $99.8-3.07 \times 10^{3}$ & 4154-6337 & $\begin{array}{l}844- \\
8.72 \times 10^{5}\end{array}$ & $1507-9.18 \times 10^{5}$ & $1.84 \times 10^{3}$ & $1.74 \times 10^{3}$ & 62.9 \\
\hline PCB-28 & 28.6 & $15.1-36.4$ & 85.8 & 66.2 & $622-1142$ & 4.00 & 6.22 & $71.4-154$ & $136-289$ & $67.0-648$ & $225-677$ & 67.5 & 379 & 12.6 \\
\hline PCB-52 & 1.12 & $3.80-30.1$ & 48.0 & 0.90 & $1.21-24.6$ & 1.11 & 2.79 & $1.07-4410$ & $3.83-74.4$ & $1.12-15.9$ & $2.67-5.24$ & 0.77 & 6.40 & 6.50 \\
\hline PCB-77 & 15.7 & $8.30-72.8$ & 62.9 & 91.0 & $341-670$ & 0.96 & 5.82 & $4.31-27.0$ & $51.5-230$ & $24.1-630$ & $88.9-620$ & 85.9 & 406 & 1.49 \\
\hline PCB-81 & ND & ND & ND & ND & ND-0.06 & 0.15 & ND & ND & ND & ND & ND & 0.26 & ND & ND \\
\hline PCB-105 & 0.04 & ND-0.03 & 0.07 & 0.05 & ND & 0.13 & 0.02 & $0.04-0.61$ & $0.04-0.07$ & $0.04-0.14$ & ND-0.09 & ND & 0.08 & 0.06 \\
\hline PCB-114 & ND & ND & ND & ND & ND-0.02 & 0.03 & ND & ND-0.01 & ND & ND-0.02 & ND & ND & ND & 0.01 \\
\hline PCB-118 & 0.08 & $0.12-0.15$ & 0.28 & 0.29 & $0.17-1.26$ & 0.52 & 0.07 & $0.05-0.14$ & $0.12-0.22$ & $0.12-0.63$ & ND-0.40 & 0.05 & 0.21 & 0.16 \\
\hline PCB-123 & ND & ND & 0.10 & 0.19 & ND-0.19 & 0.06 & ND & ND & ND-0.02 & ND-0.04 & ND-0.29 & ND & ND & ND \\
\hline PCB-126 & ND & $0.11-0.36$ & 0.50 & 0.11 & $13.5-33.5$ & 0.04 & 0.23 & ND-0.12 & $0.25-0.77$ & $0.14-5.88$ & $0.65-5.93$ & 0.15 & 0.55 & ND \\
\hline PCB-156 & ND & ND & ND & ND & ND-0.07 & 0.03 & ND & ND & ND-0.02 & ND-0.01 & ND & ND & ND & 0.02 \\
\hline PCB-157 & ND & ND & ND & ND & ND & 0.02 & ND & ND & ND & ND & ND & ND & ND & ND \\
\hline PCB-167 & ND & ND & 0.01 & ND & $0.08-0.62$ & 0.02 & ND & ND & ND-0.04 & ND & ND & ND & ND & 0.01 \\
\hline PCB-169 & ND & ND-0.16 & 0.20 & 0.04 & $10.1-26.2$ & ND & 0.17 & ND-0.03 & ND-0.12 & ND-0.12 & ND-0.23 & 0.03 & 0.05 & ND \\
\hline PCB-189 & ND & ND & $\mathrm{ND}$ & ND & ND-0.36 & ND & ND & ND & ND & ND & ND & ND & ND & ND \\
\hline PCB-101 & 0.25 & ND & 0.66 & 0.30 & $0.06-0.34$ & 0.62 & ND & ND-0.19 & ND-0.42 & ND-0.33 & ND-0.81 & ND & ND & 0.07 \\
\hline PCB-138 & 0.11 & ND-0.09 & 0.15 & 0.11 & $0.07-0.55$ & 0.53 & 0.12 & $0.04-0.16$ & $0.09-0.22$ & ND-0.2 & ND-0.13 & 0.03 & 0.07 & 0.19 \\
\hline PCB-153 & 0.14 & $0.21-2.08$ & 0.69 & 0.55 & $0.67-1.14$ & 0.52 & 0.18 & $0.04-90.6$ & $0.13-0.33$ & $0.19-0.24$ & $0.65-0.98$ & 0.08 & 0.15 & 0.22 \\
\hline PCB-180 & ND & ND-0.05 & 0.06 & 0.04 & $0.18-0.56$ & 0.13 & 0.05 & ND-0.05 & ND-0.16 & ND-0.07 & ND-0.05 & ND & ND & 0.04 \\
\hline PCB-209 & 0.07 & ND-0.11 & 0.04 & ND & $0.04-0.21$ & 0.14 & 0.06 & ND-0.08 & $0.11-0.83$ & $0.05-0.18$ & $\mathrm{ND}$ & 0.06 & 2.67 & 0.07 \\
\hline $\begin{array}{l}\sum_{6 \text { indicator }} \\
\text { PCBs }\end{array}$ & 30.2 & $19.3-68.5$ & 135 & 68.0 & $624-1.17 \times 10^{3}$ & 6.90 & 9.37 & $72.6-4.65 \times 10^{3}$ & 199-293 & $69.4-664$ & $232-681$ & 68.4 & 385 & 19.6 \\
\hline$\sum_{20} \mathrm{PCBs}$ & 290 & $\begin{array}{l}77.4- \\
1.95 \times 10^{4}\end{array}$ & 364 & 388 & $63 \times 10^{3}-2.76 \times 10^{3}$ & 50.7 & 104 & $\begin{array}{l}1.16 \times 10^{3}- \\
4.76 \times 10^{3}\end{array}$ & $\begin{array}{l}4.40 \times 10^{3}- \\
6.86 \times 10^{3}\end{array}$ & $\begin{array}{l}983- \\
8.73 \times 10^{5}\end{array}$ & $\begin{array}{l}1.83 \times 10^{3}- \\
9.19 \times 10^{5}\end{array}$ & $1.99 \times 10^{3}$ & $2.54 \times 10^{3}$ & 84.3 \\
\hline $\mathrm{WHO}_{2005}$-TEQ & 1.58 & $16.9-43.5$ & 62.0 & 21.6 & $\begin{array}{l}1.69 \times 10^{3}- \\
4.21 \times 10^{3}\end{array}$ & 4.13 & 25.8 & $0.43-16.0$ & $31.4-86.1$ & $21.3-651$ & $80.2-655$ & 24.7 & 97.4 & 0.16 \\
\hline
\end{tabular}

\footnotetext{
ND: not detected or below the LOD

aemon pigment.

Middle pigment.

Bisacetoacetic arylides pigment.
}

${ }^{\mathrm{d}}$ Quinophthalone pigment. 
such as P.Y.191 in this study. In turn, disazo pigments also can be further classified into two subgroups according to the corresponding diazonium salts. The dominant diazo groups are diarylide yellow pigments and disazo pyrazolones which contain di- and tetra-substituted diaminodiphenyls (for instance 3,3'-dichlorobenzidine, 3,3'-dimethoxybenzidine, and 2, 2', 5, 5'-tetrachlorobenzidine) as diazonium salts, and make up about $25 \%$ of the worldwide color organic pigments production (Savastano, 2007). Different with diarylide yellow pigments, bisacetoacetic arylides pigments are obtained by diazotization of aromatic amines and then coupled onto bisacetoacetic arylides such as P.Y.16 in this study. Besides, quinophthalone pigment has a polycyclic structure derived from quinaldine and phthalic anhydride such as P.Y.138 in this study. The detail information of the pigment samples and principal molecular structures are shown in Table S1 (Supporting Information).

\subsection{Concentrations and distribution of PCBs}

Table 1 summarizes the detected concentrations of individual PCB congeners in all sampled pigment products. $\sum_{20} \mathrm{PCBs}$ were in the range of $50.8-9.19 \times 10^{5} \mathrm{ng} \mathrm{g}^{-1}$ with a median value of $1.76 \times 10^{3} \mathrm{ng} \mathrm{g}^{-1}$. The PCB levels varied widely among the different kinds of pigments from the same manufacturer and also among the same type of pigment collected from different plants. The levels were much higher than the total PCB concentrations (209 PCB congeners) in the pigments reported by $\mathrm{Hu}$ and Hornbuckle (2010) (2-200 $\left.\mathrm{ng} \mathrm{g}^{-1}\right)$, and comparable to the result investigted by Japan Dyestuff and Industrial Chemicals Association (METI, 2012). Generally, diarylide yellow pigment samples contained much higher levels of PCBs than the other types of pigments. As shown in Table 1, much higher PCB concentrations were detected in pigments from plant $C\left(1.99 \times 10^{3}-9.19 \times 10^{5} \mathrm{ng} \mathrm{g}^{-1}\right.$, median value $1.95 \times 10^{4} \mathrm{ng} \mathrm{g}^{-1}$ ) followed by those from plant B (983$6.86 \times 10^{3} \mathrm{ng} \mathrm{g}^{-1}$, median value $2.76 \times 10^{3} \mathrm{ng} \mathrm{g}^{-1}$ ) and from plant A (50.7-6.25 $\times 10^{3} \mathrm{ng} \mathrm{g}^{-1}$, median value $\left.775 \mathrm{ng} \mathrm{g}^{-1}\right)$. It should be noted that the PCB levels in pigments P.Y.14 (C) $\left(8.73 \times 10^{5} \mathrm{ng} \mathrm{g}^{-1}\right)$ and P.Y.17 (C) $\left(9.19 \times 10^{5} \mathrm{ng} \mathrm{g}^{-1}\right)$ were approximately 20 times higher than the upper bound limits $(50 \mathrm{ppm})$ in commercial

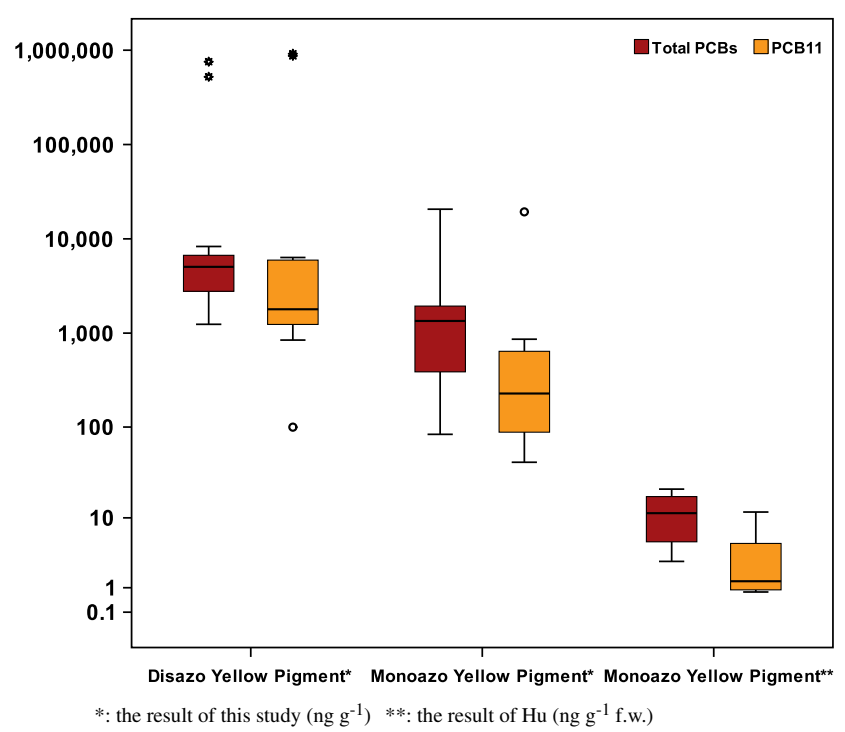

Fig. 2. Comparison of total PCBs (sum of mono- to deca-PCB congeners) and PCB11 concentrations in yellow pigments between our study and $\mathrm{Hu}$ and Hornbuckle (2010).

diarylide or phthalocyanin pigments regulated by EPA in 1979 (U.S.EPA, 1979). P.Y.14 and P.Y.17 are used in polyolefins, packaging and textile printing ink industries in large amounts, especially P.Y.17 which is used primarily in the printing ink field and applied in a variety of packaging printing inks, and interior linings of cans and other products due to its high transparency (Herbst and Hunger, 2004). $\sum{ }_{20}$ PCBs of P.Y.14 (C) and P.Y.17 (C) also exceeded the permission level of European Resolution AP (89)1 (Council of Europe, 1989), which regulated that the concentration of PCBs in colorant, used for the coloration of food packing materials in plastics, should not exceed $25 \mathrm{mg} \mathrm{kg}^{-1}$. The concentrations of indicator PCBs were in the range of $6.90-4.65 \times 10^{3} \mathrm{ng}^{-1}$ (as shown in Table 1), and it was much higher than that in chemically

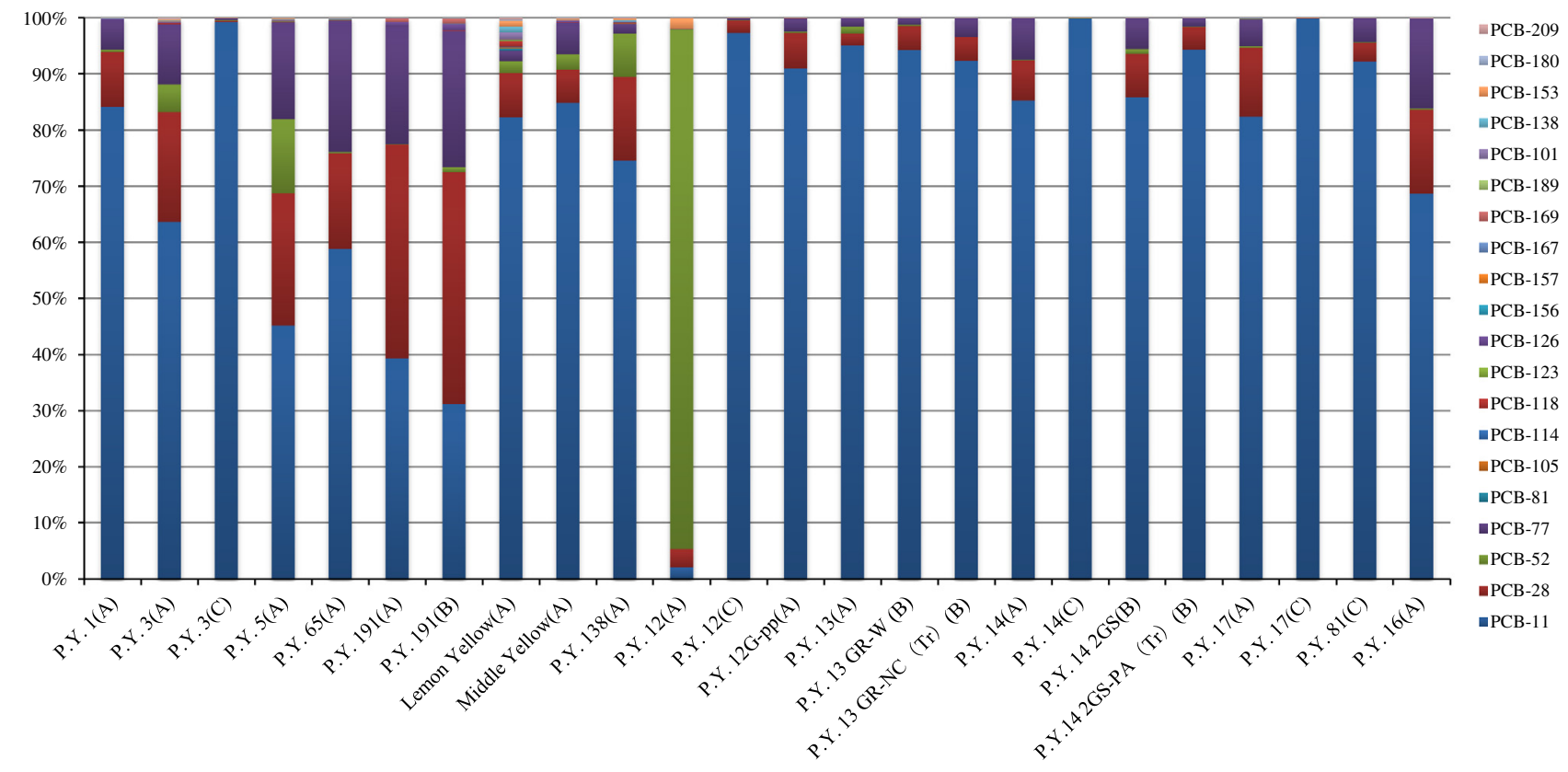

Fig. 1. Relative distribution of 20 analyzed congeners in the yellow pigment samples. 

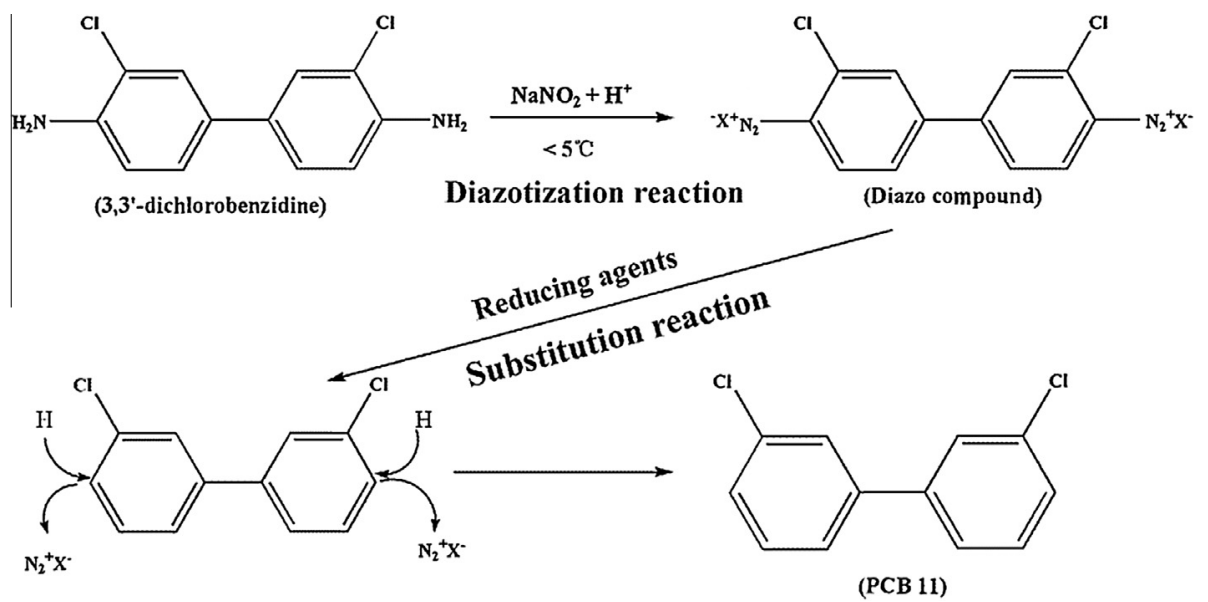

Fig. 3. Possible pathway for generating PCB 11 as a by-product from the synthesis of diarylide yellow pigments.

degraded-transformer oil (0.70-4.70 $\mathrm{ng} \mathrm{g}^{-1}$ ) and PCBs free oil (ND$1.7 \mathrm{ng} \mathrm{g}^{-1}$ ) reported by Takasuga et al. (2006). The sum of indicator PCBs in diarylide yellow pigments were in some cases higher and silimar to PCBs fortified transformer oil (131-218 $\mathrm{ng} \mathrm{g}^{-1}$ ) and PCBs polluted transformer oil (105-195 $\mathrm{ng} \mathrm{g}^{-1}$ ) (Takasuga et al., 2006).

\subsection{Concentrations and distribution of $P C B 11$ in pigments}

Among the 20 analyzed PCB congeners, PCB 11 was detected in all yellow pigments with high concentrations which ranged from 41.7 to $9.18 \times 10^{5} \mathrm{ng} \mathrm{g}^{-1}$ with a median value of $-1.14 \times 10^{3}$ $\mathrm{ng} \mathrm{g}^{-1}$, which accounted for $85.5 \%$ (median value) of $\sum_{20} \mathrm{PCBs}$ and even up to $99.8 \%$ in P.Y.17 (C) (Fig. 1). Especially in diarylide yellow pigments diazotized with 3,3'-dichlorobenzidine (DCB), the percentage of PCB 11 was as high as $92.3 \%$ (median value) with an exception of $2.10 \%$ in P.Y.12 (A). The PCB 11 concentrations were much higher than the result of the same type pigment reported by Hu and Hornbuckle (2010) (Fig. 2). Significant differences in concentrations of PCB 11 were observed between disazo pigments and monoazo pigments collected from the same plant $(p<0.05)$. The level of PCB 11 in diarylide yellow pigments was the highest among the pigments collected in this investigation (Fig. 2). A disazo pigment (P.Y.16 (A)) and a kind of monoazo pigment (P.Y.191) were found containing similar level of PCB 11 as diarylide yellow pigments from the same plant, although they have different chemical structures and synthesis pathways.

In order to improve the application performance, crystal modality and the distribution of the particulate size of the pigments, different types of dispersants (alkyl sulfonate, sulfate, sodium dodecylbenzene sulfonate, polymer dispersants, etc.) are added in the manufacturing processes (generally added at the end of synthetic process) to generate a variety of products with the same base chemical structure such as the group of P.Y.12 and P.Y.12GPP, group of P.Y.13, P.Y.13 GR-W, P.Y.13 GR-NC (Tr), and group of P.Y.14, P.Y.14 2GS, P.Y.14 2GS-PA (Tr). For these group of products manufactured in the same plant, the concentrations of PCB 11 varied widely and no clear correlation were found between the PCB congeners of the same type of pigments $(p>0.05)$, which may indicate that the additives could affect the formation of these PCB congeners. In three plants, much higher concentrations of PCB 11 were detected in plant $\mathrm{C}$, not only for the diarylide yellow pigments but also for monoazo pigments just like P.Y.3(C), of which the concentration was approximately 400 times higher than that in P.Y.3 (A) and 100 times (median value) higher than that in other monoazo yellow pigments, futhermore, percentage of PCB 11 exceed $90 \%$ in all pigments collected from Plant C including the monoazo yellow pigment P.Y.3 (C) (99.3\%) (Fig. 1). This discrepancy in levels of PCB 11 from different plants might be due to differences in raw materials, manufacturing techniques and conditions.

\subsection{Distribution pattern of other PCBs in pigments}

Although PCB 11 was the dominant congener in the pigment samples, the levels of some other PCBs were also very high. The concentrations of two indicator PCBs (PCB 28, 52) and one dioxin-like $\mathrm{PCB}$ congener (PCB 77) were in the range of $4.00-1.14 \times 10^{3} \mathrm{ng} \mathrm{g}^{-1}$ (median value $81.0 \mathrm{ng} \mathrm{g}^{-1}$ ), $0.77-4.41 \times$ $10^{3} \mathrm{ng} \mathrm{g}^{-1} \quad\left(38.2 \mathrm{ng} \mathrm{g}^{-1}\right)$, and $0.96-670 \mathrm{ng} \mathrm{g}^{-1} \quad\left(67.9 \mathrm{ng} \mathrm{g}^{-1}\right)$, respectively. A strong linear relationship was found between $\mathrm{PCB}$ 28 and PCB 77 (Pearson's correlation $r=0.94, p<0.01$ ), PCB 11 and PCB $77(r=0.68, p<0.01)$, PCB11 and PCB28 $(r=0.48$, $p<0.05$ ). There was no clear correlation between PCB 52 and the other three congeners (PCB 11, PCB 28, and PCB 77) $(r<0.2$, $p>0.05$ ). Hu and Hornbuckle (2010) found previously that PCB 209 accounted for more than $30 \%$ in phthalocyanine green pigments but in this study this fully chlorinated congener was found only at low levels in all yellow pigment samples.

It is exceptional that PCB 52 had a high percentage of $\sum_{20} \mathrm{PCBs}$ (92.0\%) in pigment of P.Y.12 (A) diazotized with 3,3'-dichlorobenzidine, and it is also contradicts to the previous findings by $\mathrm{Hu}$ and Hornbuckle (2010). But the reason is not clear.

\subsection{WHO-TEQ values in the pigments}

The TEQ values of PCBs of the 24 yellow pigment samples were calculated based on the $\mathrm{WHO}_{2005}$-TEFs (Van den Berg et al., 2006), and they were in the range of $0.16-4.21 \times 10^{3} \mathrm{ng} \mathrm{kg}^{-1}$ (average value of $328 \mathrm{ng} \mathrm{kg}^{-1}$ and median value of $30.3 \mathrm{ng} \mathrm{kg}^{-1}$ ) with five dioxin-like PCBs detected in most of pigment samples. The highest TEQ values were observed in P.Y.191 (B) $\left(4.21 \times 10^{3} \mathrm{ng} \mathrm{kg}^{-1}\right)(\mathrm{pyr}-$ azolone pigment), followed by P.Y.191 (A) $\left(1.69 \times 10^{3} \mathrm{ng} \mathrm{kg}^{-1}\right)$, P.Y.17 (C) (655 $\mathrm{ng} \mathrm{kg}^{-1}$ ), and P.Y.14 (C) (651 $\mathrm{ng} \mathrm{kg}^{-1}$ ) which was mainly due to the relatively higher concentrations of PCB 126 with the highest toxic equivalent factor (TEF). The high TEQ of the pigments may pose higher exposure risk for occupational workers. As the major contributors to total PCBs, PCB 11, 28, and 52 should not be ignored, which have been reported producing a great variety of biological effects such as neurochemical effects, cognitive impairment, and development toxicity (Chu et al., 1996; Kodavanti, 2005; Llansola et al., 2010; Lilienthal et al., 2011). 


\subsection{Possible pathways of $P C B 11$ into the pigment products}

Theoretically, there are two possible pathways for PCB 11 to be introduced into the pigment.

(1) It may be through the raw materials employed during the synthesis processes. However, it is in contradiction with the fact that the concentrations of PCB 11 varied widely in pigments collected from the same plant, particularly for pigments with the same chemical structures. It indicated that the contribution of raw materials to concentration of $\mathrm{PCB}$ 11 was limited.

(2) PCB 11 could be generated as a by-product during the manufacturing process of the pigment. Diazotization and coupling are two important reactions during the synthesis of the azo pigment. The diazo compound will be transformed to diazonium salt by a diazotizatiom reaction with nitrosating agents, and diazonium salt could be unstable when weak reducing agents are present, which results in the replacement of diazo amino group by hydrogen atom. Generally, 3,3'-dichlorobenzidine and 2,2',5,5'-tetrachlorobenzidine are technically important diazo components for the diarylide yellow pigments (Herbst and Hunger, 2004), and they could produce PCB 11 through this mechanism and/or the coupling of unsaturated aliphatic compounds at lower $\mathrm{pHs}$ and in presence of reducing agents (Solomons and Fryhle, 2009) (Fig. 3). Aromatic amine and hydrochloric acid were frequently used in synthesis of monoazo pigments, in that, the free radical mechanism and the free radical rearrangement of chlorine positions might play an important role in generating PCB 11 and other PCB congeners (Hu and Hornbuckle, 2010). This mechanism could explain the distributions of PCB 11 in most pigments in this study. However, it could not explain the distribution of PCB 52 in P.Y.12 (A) and P.Y.81 (C), which should be investigated further.

\section{Conclusions}

In the present study, we firstly investigated the concentration and distribution of PCBs in 24 yellow organic pigments produced in China. The levels of $\sum_{20} \mathrm{PCBs}$ were mostly higher compared to previous reports from other countries, and in some pigment samples, $\sum{ }_{20}$ PCBs exceeded the permission levels of US EPA and Council of Europe regulations. The congener profiles were distinguishly different with previous studies, and PCB 11 was the predominant congener in most yellow pigments, which even contributed to more than $90 \%$ of $\sum_{20} \mathrm{PCBs}$ in diarylide yellow pigments. Further investigation on the risk of PCBs in the yellow pigments found that the WHO-TEQ values were at high levels, suggesting they might pose a potential risk to humans and the environment. The formation mechanism of PCB 11 and health risk of pigment are still necessary to further study.

\section{Acknowledgement}

This study was financially supported by National Natural Science Foundation of China (Nos. 21277165, 41276195, and 21107121) and Chinese Academy of Sciences (YSW2013B01).

\section{Appendix A. Supplementary material}

Supplementary data associated with this article can be found, in the online version, at http://dx.doi.org/10.1016/j.chemosphere.2013. 09.075.

\section{References}

Baek, S.Y., Jurng J. Chang, Y.S, 2013. Spatial distribution of polychlorinated biphenyls, organochlorine pesticides, and dechlorane plus in Northeast Asia. Atmos. Environ. 64, 40-46.

Ballschmiter, K.H., Froescheis, O., Jarman, W.M., Caillet, G., 1997. Contamination of the deep-sea. Mar. Pollut. Bull. 34, 288-289.

Basu, I., Arnold, K.A., Vanier, M., Hites, R.A., 2009. Partial pressures of PCB-11 in air from several great lakes sites. Environ. Sci. Technol. 43, 6488-6492.

CDIA, 2009. Chinese Dyestuff Industry-present situation and development http:// www.chinainterdye.com/en/newstotwo.aspx?id=97.

Chu, I., Villeneuve, D.C., Yagminas, A., Lecavalier, P., Poon, R., Hakansson, H., Ahlborg, U.G., Valli, V.E., Kennedy, S.W., Bergman, A., Seegal, R.F., Feeley, M., 1996. Toxicity of $2,4,4^{\prime}$-trichlorobiphenyl in rats following 90-day dietary exposure. J. Toxicol. Environ. Health. 49, 301-318.

Council of Europe, 1989. Resolution AP (89) 1 on the use of colorants in plastic materials coming into contact with food, adopted by the committee of ministers at the 428th meeting of the ministers' deputies.

Dang, V.D., Walters, D.M., Lee, C.M., 2012. Historical changes in polychlorinated biphenyls contaminated sediments. Am. J. Environ. Sci. 8, 11-15.

DSEWPC, 1998. National Advisory Body on Scheduled Wastes: Monitoring of PCBs in Australia, Department of Sustainability, Environment, Water, Population and Communities. <http://www.environment.gov.au/settlements/publications/ chemicals/scheduled-waste/pubs/pcbmonitoring.pdf>.

ETAD, BCMA, VdMI, EPSOM, 1995. Safe Handling of Pigments, European Edition, in English, French, German and Spanish language.

Grossman, E., 2013. Nonlegacy PCBs: pigment manufacturing by-products get a second look. Environ. Health Perspect. 121, A86-A93.

Herbst, W., Hunger, K., 2004. Industrial organic pigments: production, properties, applications. third ed.. Weinheim, Germany.

HSDB, 2003. Hazardous Substances Database. National Library of Medicine, Bethesda, Maryland. http://toxnet.nlm.nih.gov/cgi-bin/sis/search/f?./temp/ Da4zBm:1.

Hu, D.F., Hornbuckle, K.C., 2010. Inadvertent polychlorinated biphenyls in commercial paint pigments. Environ. Sci. Technol. 44, 2822-2827.

Hu, D.F., Martinez, A., Hornbuckle, K.C., 2008. Discovery of non-aroclor PCB (3,3'-Dichlorobiphenyl) in Chicago Air. Environ. Sci. Technol. 42, 78737877.

King, T.L., Yeats, P., Hellou, J., Niven, S., 2002. Tracing the source of 3,3'dichlorobiphenyl found in samples collected in and around Halifax Harbour. Mar. Pollut. Bull. 44, 590-596.

Kodavanti, P.R., 2005. Neurotoxicity of persistent organic pollutants: possible mode(s) of action and further considerations. Dose Response 3, 273-305.

Li, Y.M., Geng, D.W., Hu, Y.B., Wang, P., Zhang, Q.H., Jiang, G.B., 2012a. Levels and distribution of polychlorinated biphenyls in the atmosphere close to chinese great wall station, antarctica: results from XAD-resin passive air sampling. Chin. Sci. Bull. 57, 1499-1503.

Li, Y.M., Geng, D.W., Liu, F.B., Wang, T., Wang, P., Zhang, Q.H., Jiang, G.B., 2012b. Study of PCBs and PBDEs in King George Island, Antarctica, using PUF passive air sampling. Atmos. Environ. 51, 140-145.

Lilienthal, H., Heikkinen, P., Andersson, P.L., van der Ven, L.T.M., Viluksela, M., 2011. Auditory effects of developmental exposure to purity-controlled polychlorinated biphenyls (PCB52 and PCB180) in rats. Toxicol. Sci. 122, $100-$ 111.

Litten, S., Fowler, B.I., Luszniak, D., 2002. Identification of a novel PCB source through analysis of 209 PCB congeners by US EPA modified method 1668 . Chemosphere 46, 1457-1459.

Liu, H.X., Zhang, Q.H., Cai, Z.W., Li, A., Wang, Y.W., Jiang, G.B., 2006. Separation of polybrominated diphenyl ethers, polychlorinated biphenyls, polychlorinated dibenzo-p-dioxins and dibenzo-furans in environmental samples using silica gel and florisil fractionation chromatography. Anal. Chim. Acta 557, 314-320.

Llansola, M., Montoliu, C., Boix, J., Felipo, V., 2010. Polychlorinated biphenyls PCB 52, PCB 180, and PCB 138 impair the glutamate-nitric oxide-cGMP pathway in cerebellar neurons in culture by different mechanisms. Chem. Res. Toxicol. 23, 813-820.

METI, 2012. Summarized Results of the Second Investigation into the Presence of Polychlorinated Biphenyls (PCBs) as By-Products in Organic Pigments [press release]. In: Japanese Ministry of Economy, T., and Industry (Ed.), Tokyo, Japan. <http://www meti.go.jp/english/press/2012/0830 01.html>.

O'Reilly, J., Yarto, M., 2010. The status of PCBs in North America: Follow-up to the north american regional action plan on polychlorinated biphenyls, <http:// www.cec.org/Storage/98/9746 QA1020b_NP_PCB_NARAP_report_Sep2010_en.pdf >.

Rastogi, S.C., 1992. Investigation of isomer specific polychlorinated-biphenyls in printing inks. Bull. Environ. Contam. Toxicol. 48, 567-571.

Rodenburg, L.A., Guo, J., Du, S.Y., Cavallo, G.J., 2010. Evidence for unique and ubiquitous environmental sources of 3,3'-dichlorobiphenyl (PCB 11). Environ. Sci. Technol. 44, 2816-2821.

Savastano, D., 2007. The Pigment Report: Although 2006 was a year of improvement, pigment manufacturers are coping with a wide variety of challenges, including raw material pricing and supply issues and overcapacity. Ink World.

Shain, W., Bush, B., Seegal, R., 1991. Neurotoxicity of polychlorinated-biphenyls structure-activity relationship of individual congeners. Toxicol Appl Pharm 111, $33-42$. 
Shang, H.T., Wang, P., Wang, T., Wang, Y.W., Zhang, H.D., Fu, J.J., Ren, D.W., Chen, W.H., Zhang, Q.H., Jiang, G.B., 2013. Bioaccumulation of PCDD/Fs, PCBs and PBDEs by earthworms in field soils of an E-waste dismantling area in China. Environ. Int. 54, 54-58.

Solomons, T.W.G., Fryhle, C.B., 2009. Organic Chemistry, 10th ed. John Wiley \& Sons Ltd., New York.

Srogi, K., 2008. Levels and congener distributions of PCDDs, PCDFs and dioxinlike PCBs in environmental and human samples: a review. Environ. Chem. Lett. 6, 1-28.

Stegeman, J.J., Schlezinger, J.J., Craddock, K.E., Tillitt, D.E., 2001. Cytochrome P450 1A expression in midwater fishes: Potential effects of chemical contaminants in remote oceanic zones. Environ. Sci. Technol. 35, 54-62.

Takasuga, T., Senthilkumar, K., Matsumura, T., Shiozaki, K., Sakai, S.I., 2006. Isotope dilution analysis of polychlorinated biphenyls (PCBs) in transformer oil and global commercial PCB formulations by high resolution gas chromatography-high resolution mass spectrometry. Chemosphere 62, 469484.

UNEP, 2001. Stockholm Convention on Persistent Organic Pollutants (POPs), Interim Secretariat for the Stockholm Convention, United Nations Environmental Programmer (UNEP) Chemicals: Geneva, Switzerland; <http://www.pops.int>.

US EPA, 1979. Polychlorinated Biphenyls (PCBs) Manufacturing, Processing, Distribution in Commerce, and Use Prohibitions; 40 Code of Federal Regulations, Environmental Protection Agency, Washington, DC, Part 761.31 (g).
US EPA, 1999a. Method 1668, Revision A: Chlorinated Biphenyl Congeners in Water Soil, Sediment, and Tissue by HRGC/HRMS. EPA No. EPA-821-R-00-002; U.S. Environmental Protection Agency, Office of Water: Washington, DC.

US EPA, 1999b. Use authorization for and distribution in commerce of non-liquid polychlorinated biphenyls. Fed. Regist. 64, 237.

Van den Berg, M., Birnbaum, L.S., Denison, M., De Vito, M., Farland, W., Feeley, M., Fiedler, H., Hakansson, H., Hanberg, A., Haws, L., Rose, M., Safe, S., Schrenk, D. Tohyama, C., Tritscher, A., Tuomisto, J., Tysklind, M., Walker, N., Peterson, R.E. 2006. The 2005 world health organization reevaluation of human and mammalian toxic equivalency factors for dioxins and dioxin-like compounds Toxicol. Sci. 93, 223-241.

Wang, P., Zhang Q.H., Wang Y.W., Wang, T. Li, X.M., Li, Y.M., Ding L., Jiang, G.B. 2009. Altitude dependence of polychlorinated biphenyls (PCBs) and polybrominated diphenyl ethers (PBDEs) in surface soil from Tibetan Plateau China. Chemosphere 76, 1498-1504.

Wang, T., Wang, Y.W., Fu, J.J., Wang, P., Li, Y.M., Zhang, Q.H., Jiang, G.B., 2010 Characteristic accumulation and soil penetration of polychlorinated biphenyls and polybrominated diphenyl ethers in wastewater irrigated farmlands Chemosphere 81, 1045-1051.

Wang, P., Zhang, Q.H., Wang, T., Chen, W.H., Ren, D.W., Li, Y.M., Jiang, G.B., 2012 PCBs and PBDEs in environmental samples from King George Island and Ardley Island, Antarctica.. RSC Adv. 2, 1350-1355.

Yang, M.N., Zhang, Q.H., 2011. Reduce COD and cost in the yellow pigment production. Shanghai Dyestuff 39, 52-54. 